\title{
EFFECTS OF OXIDATION ON FATIGUE CRACK INITIATION AND PROPAGATION IN AN ADVANCED DISK ALLOY
}

\author{
R. Jiang ${ }^{1}$, N. Gao ${ }^{1}$, M. Ward ${ }^{2}$, Z. Aslam² ${ }^{2}$ J. C. Walker ${ }^{1}$, P. A. S. Reed ${ }^{1}$ \\ ${ }^{1}$ Engineering Materials Research Group, Faculty of Engineering and Environments, University of Southampton, Southampton, SO17 1BJ, \\ UK \\ ${ }^{2}$ Institute for Materials Research, School of Chemical and Process Engineering, University of Leeds, Leeds, LS2 9JT, UK
}

Keywords: Ni-based superalloy, grain boundary oxidation, fatigue crack, intergranular fracture

\begin{abstract}
Understanding the fatigue performance of aeroengine disk alloys is important for both alloy development and life prediction of disk components. In this study, fatigue crack initiation and propagation in coarse grained (CG) and fine grained (FG) Low Solvus, High Refractory (LSHR) alloy developed for disk applications have been assessed at 650 and $725^{\circ} \mathrm{C}$ by carrying out three-point bend tests in air and vacuum under a 1-1-1-1 trapezoidal waveform in combination with a surface replication procedure. Optical microscopy, scanning electron microscopy, focussed ion beam (FIB), transmission electron microscopy (TEM) and energy dispersive X-ray (EDX) spectroscopy have been employed to reveal the underlying mechanisms of fatigue crack initiation and early propagation under these fatigueoxidation conditions. The results show that FG LSHR possesses a better fatigue life although it exhibits more severe grain boundary oxidation as indicated by more intergranular fracture surfaces. Cracks mainly initiate from bulged grain boundary oxides which consist of outermost Co-rich and Ni-rich oxide complex at the surface and underneath $\mathrm{Cr} / \mathrm{Ti} / \mathrm{Al}$ oxide intrusions along the grain boundaries. Once initiated, cracks propagate mostly by the coalescence of neighboring grain boundary cracks as observed on the replicas, especially in the FG variant. Formation of these grain boundary oxides is closely related to the applied stress and the strain localization at the grain boundary, and is accompanied by $\gamma^{\prime}$ dissolution. The distribution of oxides examined by TEM-EDX suggests fatigue failure processes involve repeated cycles of oxide formation $\rightarrow$ oxide cracking $\rightarrow$ oxide formation at the crack tip $\rightarrow$ oxide cracking at the crack tip.
\end{abstract}

\section{Introduction}

Powder metallurgy (PM) Ni-based superalloys have been widely used for High Pressure (HP) disk rotor applications in aeroengines due to their excellent combined properties, i.e. high strength at elevated temperatures, good resistance to fatigue, creep, oxidation and corrosion [1,2]. Among all the properties of PM Ni-base superalloys for disk applications, fatigue is one of the most important, often limiting the overall service life. However, due to the increased operating temperatures of the HP disks, which are required to improve engine efficiency, creep and oxidation damage make increasing contributions to the fatigue failure of disk superalloys, especially under dwell-fatigue conditions, resulting in accelerated fatigue failure in terms of shorter fatigue life and/or faster crack propagation rate [3-10]. Such a phenomenon is usually associated with intergranular fracture resulting from the interaction between grain boundary (GB) oxidation/embrittlement effects and mechanical fatigue processes, and is a function of the microstructures of the investigated disk superalloys and the service conditions [3-5, 1115]. Generally, the microstructures corresponding to an improvement of fatigue performance and high temperature strength for disk superalloys are usually associated with a degradation of the creep and oxidation resistance [5-7, 16-18]. The conflicting and interlinked requirements for these microstructures to improve fatigue-creep-oxidation performance require a deep understanding of the mechanisms of fatigue, creep and oxidation under service conditions and the main microstructural factors controlling these failure processes as well as the interplay of damage between fatigue, creep and oxidation processes. Study of crack initiation and propagation mechanisms with the coupled influences of (fatigue/creep) deformationoxidation damage in disk superalloys is therefore necessary and helpful for further development of appropriate materials optimization approaches in terms of alloying design and processing techniques to improve high temperature disk performance.

In this study, we focused on assessing fatigue failure under dwell-fatigue conditions in a latest generation PM Ni-based superalloy (i.e. Low Solvus, High Refractory (LSHR) alloy [15, $19,20])$ with enhanced high temperature processing versatility due to the low solvus temperature developed by NASA for HP disk applications at higher operating temperatures. The relationship of grain boundary oxidation as a consequence of microstructure-dependent strain localization has been evaluated and linked to the resultant fatigue crack initiation and propagation.

\section{Materials and experimental procedures}

The composition (in wt.\%) of the LSHR alloy is: 20.7 Co, 12.5 $\mathrm{Cr}, 3.5 \mathrm{Ti}, 3.5 \mathrm{Al}, 4.3 \mathrm{~W}, 2.7 \mathrm{Mo}, 1.6 \mathrm{Ti}, 1.5 \mathrm{Nb}, 1.5 \mathrm{Ta}, 0.05 \mathrm{Zr}$, $0.03 \mathrm{C}, 0.03 \mathrm{~B}$, bal. Ni. The LSHR alloy powder was atomized in argon, canned, hot isostatically pressed, extruded and isothermally forged into a flat disk. Rectangular blanks were then extracted from the forged pancake, and then were supersolvus and subsolvus solution heat treated to obtain coarse grained (CG) and fine grained (FG) microstructures respectively. The supersolvus solution heat treatment was conducted at $1171{ }^{\circ} \mathrm{C}$ for 1 hour followed by a cooling of $72{ }^{\circ} \mathrm{C} / \mathrm{min}$, and the subsolvus solution heat treatment was conducted at $1135^{\circ} \mathrm{C}$ for 1 hour followed by a cooling of $202{ }^{\circ} \mathrm{C} / \mathrm{min}$. Subsequently the blanks were aged at 855 ${ }^{\circ} \mathrm{C}$ for 4 hours and then $755{ }^{\circ} \mathrm{C}$ for 8 hours. The microstructural features of the LSHR alloys are summarized in Table I

Table I Grain size and $\gamma^{\prime}$ size in the CG and FG LSHR alloys

\begin{tabular}{|c|c|c|c|c|}
\hline & $\begin{array}{c}\text { Grain size } \\
\text { range }(\mu \mathrm{m})\end{array}$ & $\begin{array}{c}\text { Average grain } \\
\text { size }(\mu \mathrm{m})\end{array}$ & $\begin{array}{c}\text { Primary } \\
\gamma^{\prime}(\mu \mathrm{m})\end{array}$ & $\begin{array}{c}\text { Secondary } \\
\gamma^{\prime}(\mathrm{nm})\end{array}$ \\
\hline CG LSHR & $10-140$ & $36.1 \pm 18.1$ & N/A & $153 \pm 29$ \\
FG LSHR & $4-16$ & $8.4 \pm 2.8$ & $1.7 \pm 0.5$ & $89 \pm 15$ \\
\hline
\end{tabular}


Fatigue tests were conducted on CG and FG LSHR alloys under three-point bend loading on an Instron servohydraulic testing machine in combination with a surface replication procedure. The test geometry was chosen to assess crack initiation and propagation processes in the LSHR alloy in the presence of a stress concentration. As shown in Figure 1, the dimension of the U-notch specimen is $4 \mathrm{~mm} \times 10 \mathrm{~mm} \times 53 \mathrm{~mm}$, and the radius and the depth of the notch are $2 \mathrm{~mm}$ and $1.25 \mathrm{~mm}$ respectively. The surface of the notch was ground and then was polished using dental felts and $1 \mu \mathrm{m}$ diamond polishing paste. Tests were carried out in air and vacuum $\left(\sim 5 \times 10^{-4}\right.$ mbar $)$ at 650 and $725^{\circ} \mathrm{C}$ under a $1-1-1-1(0.25 \mathrm{~Hz})$ loading waveform with a load ratio of 0.1 . The load was applied to produce a maximum nominal elastic stress $\left(\sigma_{\max }\right)$ of $1020 \mathrm{MPa}$ in the uncracked ligament, defined as the net section bending stress at the plane of the notch root calculated using simple beam theory. Tests conducted at $650{ }^{\circ} \mathrm{C}$ were run to failure to obtain the fatigue life of the LSHR alloy which was used to determine the interruption interval for the replica process of the notch root in the following tests. Interrupted tests were carried out at 650 and $725{ }^{\circ} \mathrm{C}$ to allow replicas to be made of the notch root surface to monitor crack evolution. The interrupted tests were stopped when cracks were longer than the half width of the specimen. An Olympus BX51 optical microscope (OM) was used to assess crack evolution on the replicas. A JEOL JSM 6500F field emission gun (FEG) scanning electron microscope (SEM) was used to examine the fractography and the morphology and distribution of oxides at the notch root surface formed during the fatigue test. After the interrupted test, the specimens were sectioned to examine the crack path in the bulk material and oxidation at the crack tip.

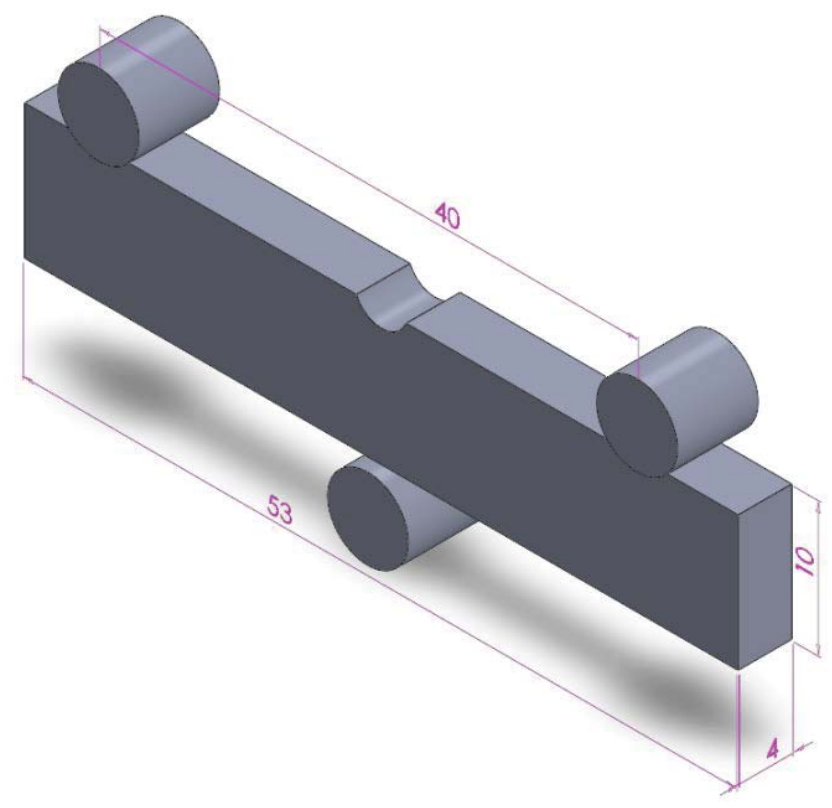

Figure 1 Schematic diagram of set-up of the fatigue test and dimension of the specimen (dimension in $\mathrm{mm}$ ).

Oxides formed during the fatigue tests were examined using TEM. TEM foils were extracted from the FG LSHR tested at 725 ${ }^{\circ} \mathrm{C}$ (to sample more grain boundaries) using a FEI NanoLab Dual Beam FIB/SEM system. The areas of interest for TEM foil extraction are the grain boundaries with and without apparent oxides as well as the interface of primary $\gamma^{\prime} / \gamma$ matrix at the notch root surface. After metallographic sectioning, in-plane TEM foils which were parallel to the crack propagation direction inside the bulk material were extracted at the crack tip. Examination of the extracted foils was carried out using a FEI Tecnai TF20 FEG TEM with an accelerating voltage of $200 \mathrm{kV}$. Energy dispersive $\mathrm{X}$-ray spectroscopy mapping was conducted around grain boundaries with and without apparent oxides as well at the primary $\gamma^{\prime} / \gamma$ matrix interface to reveal the oxide composition along with the element distribution adjacent to oxides.

\section{Results}

\section{Fatigue life of LSHR alloy}

Table II shows the fatigue life variation with testing temperature and environment. It is found that the fatigue life of LSHR alloy is significantly shortened by higher testing temperature and an oxidizing environment, indicating the marked influence of oxidation on fatigue life. Although the FG LSHR may be expected to show more severe GB oxidation at elevated temperatures, a longer fatigue life is observed at $650^{\circ} \mathrm{C} c f$. the $\mathrm{CG}$ variant. This is ascribed to the higher yield strength of the FG LSHR than that of the CG LSHR [15], resulting in less plastic strain and associated damage in each fatigue cycle that acts to counterbalance the increased GB oxidation effect.

\section{$\underline{\text { Fatigue crack initiation and propagation }}$}

Figure 2 presents the fractography of the CG and FG LSHR alloys tested in air and vacuum at 650 and $725^{\circ} \mathrm{C}$. It is found that the intergranular or transgranular features on the fracture surfaces are dependent on the degree of oxidation in the tested specimens which is associated with the grain size of the LSHR alloy, testing temperature and environment. As shown in Figure 2 (a), cracks appear to initiate from the grain boundary as indicated by the arrow in the vacuum test at $650{ }^{\circ} \mathrm{C}$ for the CG LSHR, although intergranular features are not clearly evident on the fracture surface. After intergranular crack initiation, the crack propagates in a mixed inter-transgranular mode by a short distance (approximately 1-2 grains), and then converts to completely transgranular propagation. In addition, crystallographic facets can also be seen on the fracture surface. The transition to completely transgranular crack propagation with crystallographic facets also indicates the relatively insignificant influence of oxidation on crack propagation in vacuum (low oxygen partial pressure environment). Figure 2 (b) shows the fractography of the CG LSHR tested at $650{ }^{\circ} \mathrm{C}$ in air, where an increase in intergranular fracture features is seen compared with that of the vacuum test. Increased intergranular features on the fracture surface indicate a more significant role of oxidation in crack initiation and propagation in these air tests. Figure 2 (c) presents the crack path in the bulk material after metallographic sectioning in the CG LSHR tested at $725{ }^{\circ} \mathrm{C}$ (no test was run to fracture at this temperature). It shows predominantly intergranular features on the crack path, and the crack tip appears to be intergranular and discontinuous as shown in Figure 2 (d). For the FG LSHR, a more significant degree of intergranular features is observed than in the CG LSHR, indicating the critical role of grain boundaries in oxidation. In addition, crack propagation along the interfaces of $\gamma$ matrix/primary $\gamma^{\prime}$ can also be discerned in the FG LSHR. The crack path of the FG LSHR tested at $725^{\circ} \mathrm{C}$ is not presented here, but intergranular features also dominated as seen at $650{ }^{\circ} \mathrm{C}$. 
Table II Fatigue life (in cycles) of LSHR alloy from a peak stress of $1020 \mathrm{MPa}$ and load ratio of 0.1

\begin{tabular}{|c|c|c|c|}
\hline \multirow{2}{*}{ Test conditions } & \multicolumn{2}{|c|}{ Air } & Vacuum \\
\cline { 2 - 4 } & $650^{\circ} \mathrm{C}$ & $725^{\circ} \mathrm{C}$ & $650{ }^{\circ} \mathrm{C}$ \\
\hline CG LSHR & $2460\left(2700^{*}\right)$ & $90^{*}$ & $16778\left(18625^{*}\right)$ \\
\hline FG LSHR & $7998\left(7250^{*}\right)$ & $400^{*}$ & - \\
\hline
\end{tabular}

Note: * represents that the data is from interrupted tests.
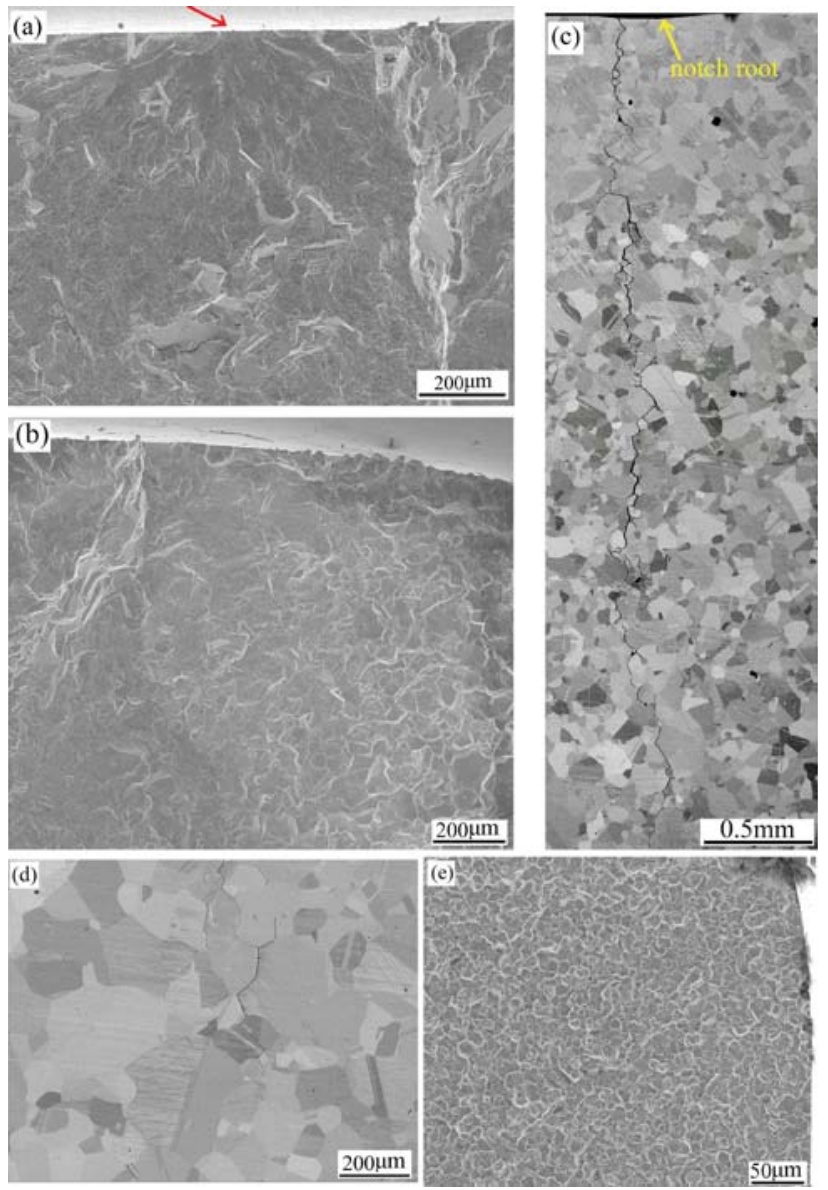

Figure 2 Fractography and crack paths in the LSHR alloy: (a) fractography of CG LSHR, $650{ }^{\circ} \mathrm{C}$, vacuum; (b) fractography of CG LSHR, $650{ }^{\circ} \mathrm{C}$, air; (c) backscatter electron image showing crack path of CG LSHR after metallographic sectioning, $725^{\circ} \mathrm{C}$, air; (d) backscatter electron image showing crack tip of CG LSHR after metallographic sectioning, $725^{\circ} \mathrm{C}$, air; and (e) fractography of FG LSHR, $650{ }^{\circ} \mathrm{C}$, air. Crack path and crack tip in (c) and (d) were taken from the polished surface (without etching).

Figure 3 shows the morphology of the notch root surface of the LSHR alloy at the end of the interrupted tests. It is interesting to note that grain boundaries are clearly revealed by the oxidation effect on the polished notch root surface, even in the CG LSHR vacuum test. Bulged oxides can be observed on some (but not all) grain boundaries. Slip bands, secondary/non-fatal intergranular cracks and grain boundary oxides can be clearly seen in all the tests for both CG and FG LSHR. The slip bands are most evident in the CG LSHR tested in air (Figures 3 (b) and (c)) perhaps due to the balance between the higher expected slip planarity of the coarse microstructure counterbalanced by the lower slip reversibility due to the absorption of oxygen at the slip bands. Although slip bands were frequently detected in the CG LSHR, no apparent slip band initiated cracking was found. The secondary cracks observed at the notch root are predominantly intergranular, indicating grain boundaries are the favored sites for crack initiation at the investigated temperatures.

Although intergranular cracks are also observed at the notch root in the vacuum test for the CG LSHR, grain boundary oxides are much less evident than in the air tests either for the CG or FG LSHR. Grain boundary oxides are much more common in the FG LSHR as shown in Figures 3 (d) and (e), especially at $725{ }^{\circ} \mathrm{C}$. Generally, the FG microstructure and higher testing temperature are associated with coarser and more densely distributed bulged grain boundary oxides. Apart from grain boundaries, oxides can also be observed at slip bands (Figure 3 (c)) and $\gamma / \gamma^{\prime}$ interfaces (Figures 3 (d) and (e)). Additionally, it is found that cracks occasionally cut through primary $\gamma^{\prime}$ (located at grain boundaries) as highlighted by the red arrows shown in Figure 3 (d).

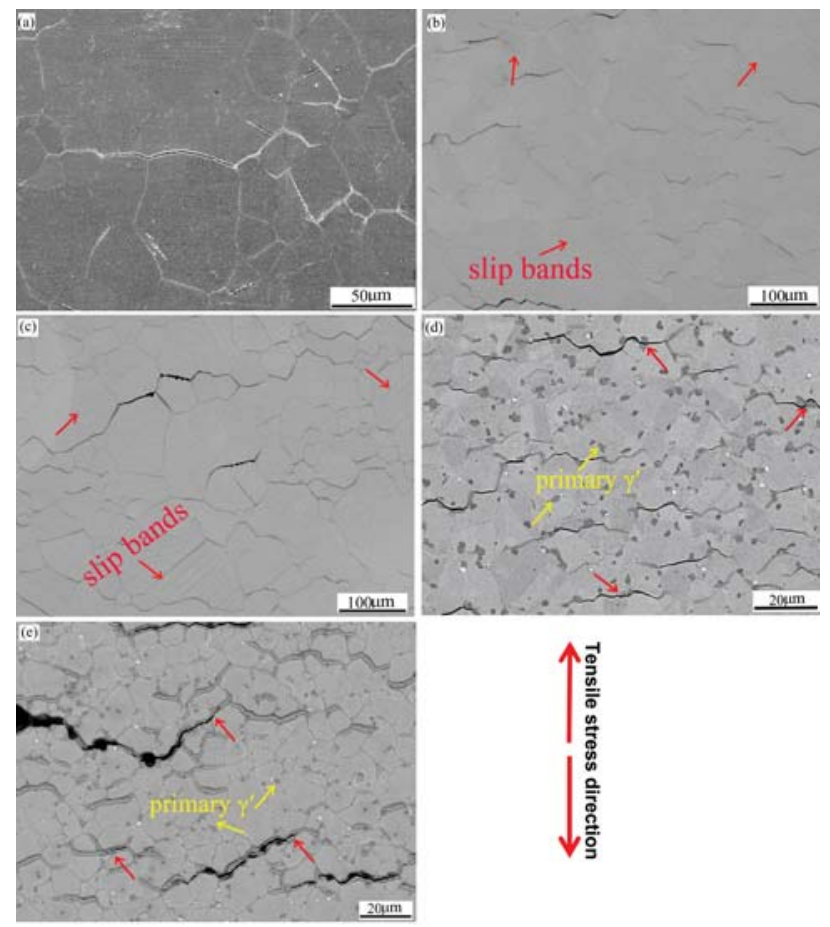

Figure 3 SEM images showing morphology of notch root surface in (a) CG LSHR, $650{ }^{\circ} \mathrm{C}$, vacuum; (b) CG LSHR, $650{ }^{\circ} \mathrm{C}$, air; (c) CG LSHR, $725{ }^{\circ} \mathrm{C}$, air; (d) FG LSHR, $650{ }^{\circ} \mathrm{C}$, air and (e) FG LSHR, $725{ }^{\circ} \mathrm{C}$, air. There is some replica compound left in the cracks after the replication procedure as shown in (c) and (e). Grain boundaries and primary $\gamma^{\prime}$ are revealed on the polished surface (without etching) due to oxidation.

One more apparent feature of the bulged oxides formed in the air tests is that the oxides attended to form at those grain boundaries which are inclined normal to the tensile stress axis in both CG and FG LSHR. However, it is noteworthy that not all the grain boundaries inclined normal to this tensile stress axis are decorated with bulged oxides, indicating that grain orientation may also influence oxide formation. In addition, bulged grain 
boundary oxide cracking can be found at the notch root as indicated by the arrows in Figure 3 (e), and the cracks propagate along these grain boundaries with bulged oxides. It is noted that the bulged GB oxides ahead of a crack tip are intact. These intact oxides may indicate that the oxide formation occurs prior to crack initiation and it is the bulged oxide cracking which results in crack initiation.

Morphologies of the oxides formed at grain boundaries and $\gamma / \gamma^{\prime}$ interfaces are presented in Figure 4. For the vacuum test, the most common oxides exhibit a somewhat discrete and circular morphology at GBs (Figure 4 (a)) and the oxidized GBs are relatively flat. For the air tests, the oxides at GBs and $\gamma / \gamma^{\prime}$ interfaces possess a more faceted morphology with a bulged height in both CG and FG LSHR (Figures 4 (b) - (d)). The different morphologies of oxides in the vacuum and air tests indicate the differing degree of GB oxidation and possibly different types of oxides. In addition, the faceted/bulged oxides are also observed within primary $\gamma^{\prime}$ precipitates as shown in Figure 4 (d). Oxide formation within primary $\gamma^{\prime}$ may be associated with the crack cutting through primary $\gamma^{\prime}$ observed in Figure 3 (d). Along the crack path, some remaining oxide particles are discerned in the rectangle-highlighted region in Figure 4 (d), which also indicates that the grain boundary cracking is related to grain boundary oxidation.
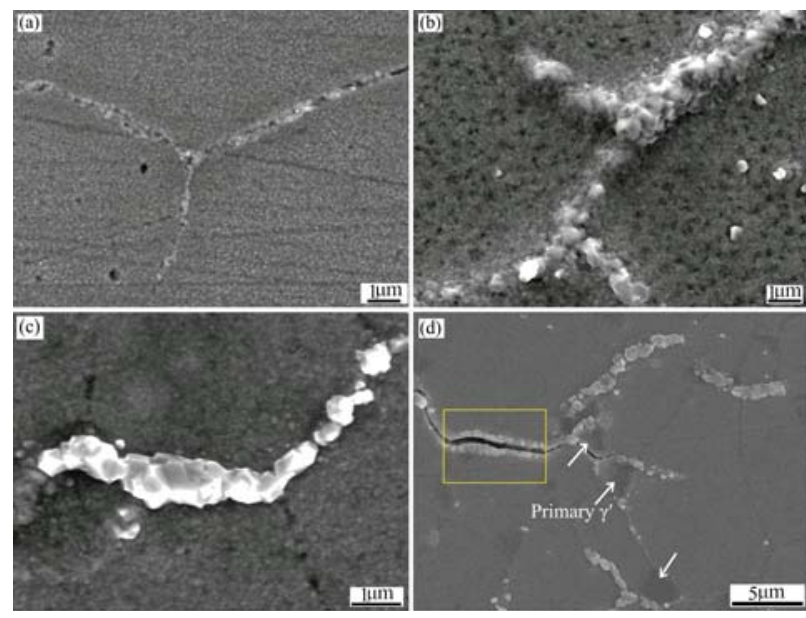

Figure 4 SEM images showing morphology of oxides at GBs and $\gamma / \gamma^{\prime}$ interfaces on the polished notch root surfaces (without etching): (a) CG LSHR, $650{ }^{\circ} \mathrm{C}$, vacuum; (b) CG LSHR, $725^{\circ} \mathrm{C}$, air; (c) FG LSHR, $650{ }^{\circ} \mathrm{C}$, air and (d) FG LSHR, $725^{\circ} \mathrm{C}$, air.

Evolution of cracks at the notch root was examined via replicas under OM. There are many cracks at the notch root surface at the investigated temperatures, and these surface cracks are predominantly intergranular although they change to be transgranular as they propagate into the depth at $650{ }^{\circ} \mathrm{C}$ in the $\mathrm{CG}$ LSHR (Figures 2 (a) and (b)). As shown in Figure 5, cracks initiate relatively late in vacuum. Although slip bands are observed on the replicas, little slip band cracking is discerned, which is consistent with the observations of the morphology of the notch root. Significant crack coalescence can be observed at the final stages of fatigue life. The crack coalescence behavior is much more significant in the air tests, especially in the FG LSHR. As shown in Figure 6, considerable numbers of small grain boundary cracks form in the FG LSHR due to the cracking of the bulged grain boundary oxides. Cracks subsequently propagate along oxidized grain boundaries at the surface. From observation of the replica record, it seems that there is no marked individual propagation of these small cracks during the majority of fatigue life before significant coalescence happens in a relatively short period at the end of fatigue life. However, a fully quantitative statistical assessment of the crack evolution process was deemed impractical due to the large number of cracks and the frequent crack coalescence events.

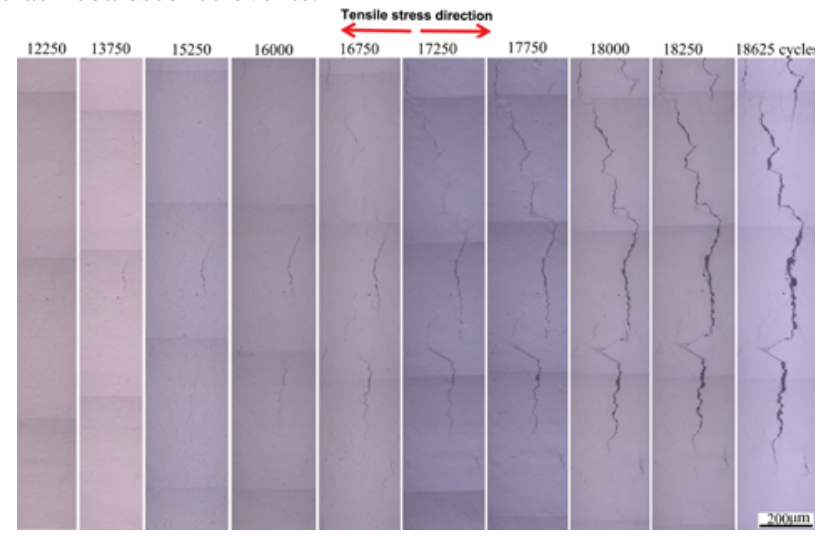

Figure 5 Optical microscope images showing crack evolution in the CG LSHR tested at $650{ }^{\circ} \mathrm{C}$ in vacuum.

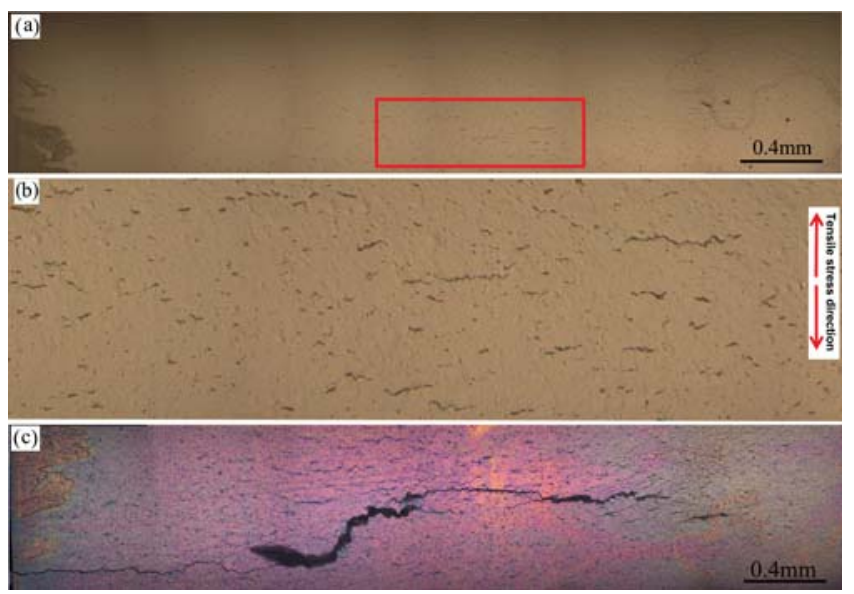

Figure 6 Optical microscope images showing crack evolution and coalescence in FG LSHR tested at $650{ }^{\circ} \mathrm{C}$ in air: (a) 6500 cycles (b) close-up of the region shown in (a), and (c) 7250 cycles.

\section{Oxidation under the fatigue load}

The oxides formed at the notch root surface and the crack tip in the bulk materials during the fatigue test were examined in the TEM. As shown in Figure 7, the TEM lamellar was extracted from a region at the notch root surface which contained grain boundaries with and without bulged oxides. It is observed that the grain boundary oxides consist of bulged parts at the surface and oxide intrusion along the grain boundary as shown in Figure 7(c). Within the $\gamma$ grain, it seems that the oxides consist of a uniform oxide scale, although the oxide scale is much thinner compared with the grain boundary oxide intrusion. Deformation twins can be seen and dislocations are found in the matrix nearby grain boundary oxides. EDX analysis shows that the bulged oxides at surface are $\mathrm{Co}$ and $\mathrm{Ni}$ oxides. Formation of $\mathrm{Co}$ and $\mathrm{Ni}$ oxides is 
associated with the dissolution of the $\gamma$ matrix around the grain boundary and the outward diffusion of $\mathrm{Co}$ and $\mathrm{Ni}$ as indicated by the elemental maps. Underneath the $\mathrm{Co}$ and $\mathrm{Ni}$ oxide scale, $\mathrm{Cr}$, $\mathrm{Ti}$ and $\mathrm{Al}$ oxides form, and these oxides penetrate along the grain boundary. The $\mathrm{Cr}, \mathrm{Ti}$ and $\mathrm{Al}$ oxide intrusion consists of a sandwich structure with $\mathrm{Cr}$ oxide in the center. Moreover, Ni-rich islands are identified within the oxide intrusion, which may be recrystallized $\gamma$ grains. In addition, $\gamma^{\prime}$ precipitates are revealed by EDX mapping. Formation of $\mathrm{Ti}$ and $\mathrm{Al}$ oxides is accompanied by $\gamma^{\prime}$ dissolution. This $\gamma^{\prime}$ dissolution can be clearly seen from the EDX mapping at the region highlighted by the rectangle in Figure 7 (c), which shows the enrichment of $\mathrm{Ni}$ and $\mathrm{Co}$ and depletion of $\mathrm{Al}$ and $\mathrm{Ti}$.
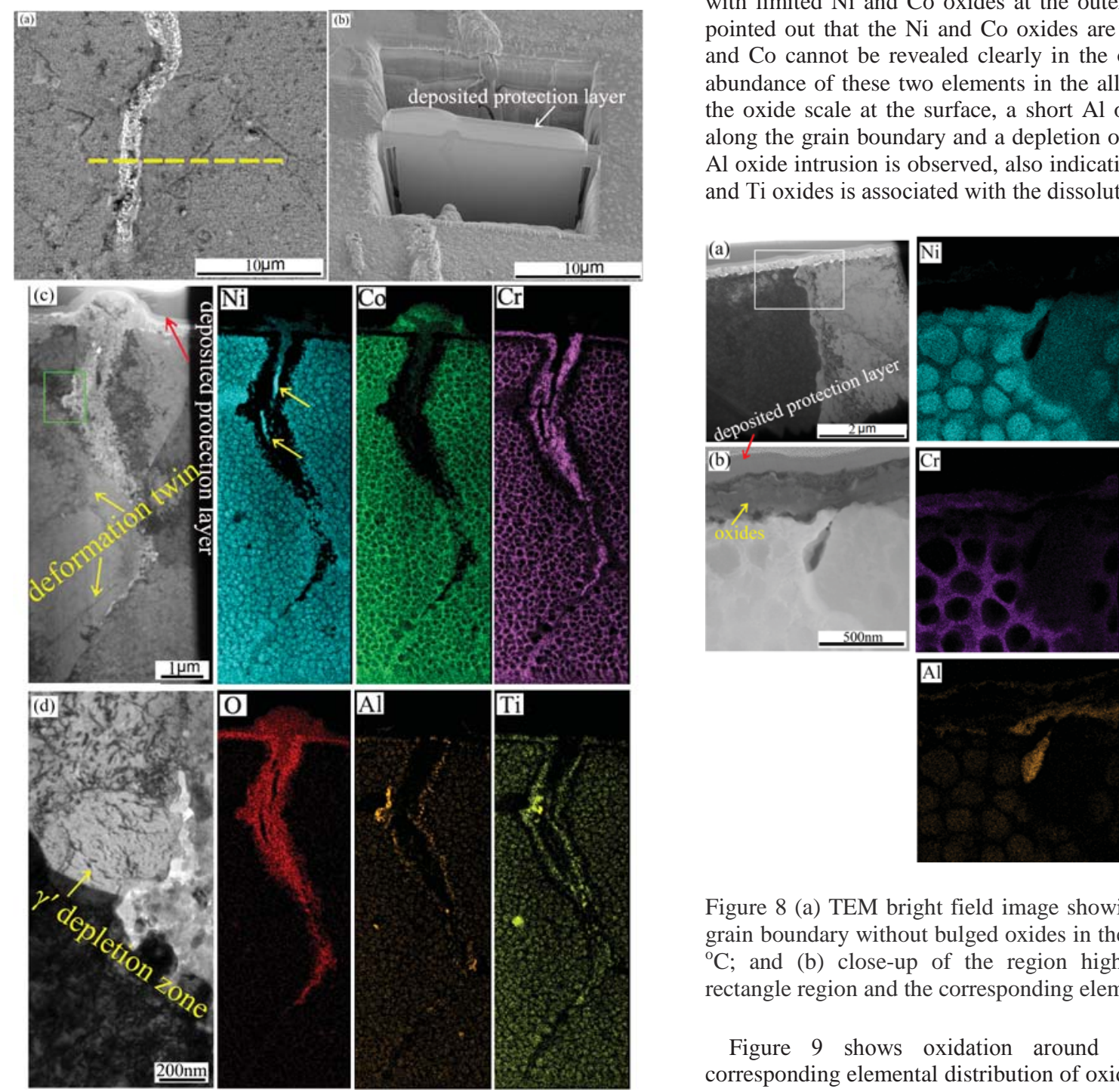

Figure 7 (a) SEM image showing the area of interest for TEM lamellar extraction in FG LSHR tested at $725{ }^{\circ} \mathrm{C}$; (b) TEM lamella in the trench before lift-out procedure. A platinum layer was deposited to protect the oxides; (c) TEM bright field image showing morphology of bulged oxides and oxide intrusion along grain boundary and the corresponding elemental maps; and (d) TEM bright field image showing close-up of the region highlighted in (c) by rectangle.
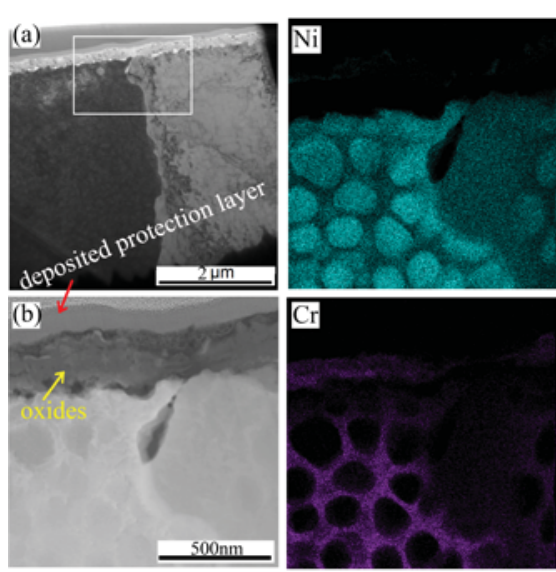

It is also interesting to notice an enrichment of $\mathrm{Ni}$ and $\mathrm{Co}$ in the middle of the $\mathrm{Cr} / \mathrm{Ti} / \mathrm{Al}$ intrusion and an enrichment of $\mathrm{Ni}$ and $\mathrm{Co}$ at the grain boundary ahead of the oxide intrusion, but it seems that this enrichment of $\mathrm{Ni}$ and $\mathrm{Co}$ is not completely associated with their oxides. It may be expected that this enrichment of $\mathrm{Ni}$ and $\mathrm{Co}$ can be rapidly oxidized once the $\mathrm{Cr} / \mathrm{Ti} / \mathrm{Al}$ oxide intrusion cracking occurs. As a consequence, a new cycle of non-selective oxidation of $\mathrm{Ni}$ and $\mathrm{Co}$ and then selective oxidation of $\mathrm{Cr} / \mathrm{Ti} / \mathrm{Al}$ may occur.

In the case of the grain boundary without bulged oxides, little oxide intrusion can be discerned. As shown in Figure 8, the thin and uniform oxide scale mainly consists of $\mathrm{Cr} / \mathrm{Ti} / \mathrm{Al}$ oxides along with limited $\mathrm{Ni}$ and $\mathrm{Co}$ oxides at the outer surface. It should be pointed out that the $\mathrm{Ni}$ and $\mathrm{Co}$ oxides are so limited that the $\mathrm{Ni}$ and Co cannot be revealed clearly in the oxide scale due to the abundance of these two elements in the alloy matrix. Apart from the oxide scale at the surface, a short $\mathrm{Al}$ oxide intrusion is seen along the grain boundary and a depletion of $\mathrm{Al}$ and $\mathrm{Ti}$ nearby the $\mathrm{Al}$ oxide intrusion is observed, also indicating the formation of $\mathrm{Al}$ and Ti oxides is associated with the dissolution of $\gamma^{\prime}$.
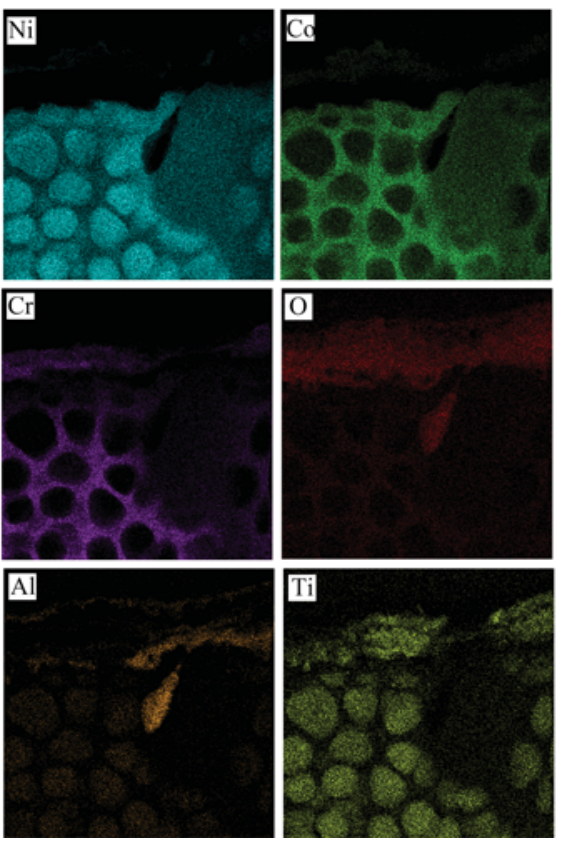

Figure 8 (a) TEM bright field image showing morphology of the grain boundary without bulged oxides in the FG LSHR test at 725 ${ }^{\circ} \mathrm{C}$; and (b) close-up of the region highlighted in (a) in the rectangle region and the corresponding elemental maps.

Figure 9 shows oxidation around primary $\gamma^{\prime}$ and the corresponding elemental distribution of oxides around the primary $\gamma^{\prime}$ at the notch root surface in the FG LSHR tested at $725{ }^{\circ} \mathrm{C}$. Oxide intrusion along a grain boundary is also observed, although the intrusion depth is shorter in comparison to Figure 7. Similar oxide scales are observed as seen in Figure 7. At the outer surface, it is a $\mathrm{Ni}$ and $\mathrm{Co}$ oxide layer. Underneath the $\mathrm{Ni}$ and $\mathrm{Co}$ oxides, $\mathrm{Cr}$, $\mathrm{Ti}$ and $\mathrm{Al}$ oxides form. It is also found that the $\mathrm{Al}$ oxide penetrates along the $\gamma^{\prime} / \gamma$ interface. Furthermore, an enrichment of $\mathrm{Cr}$ and $\mathrm{Co}$ and a depletion of $\mathrm{Ni}, \mathrm{Al}$ and $\mathrm{Ti}$ are found at the $\gamma^{\prime} / \gamma$ interface. 
(a)

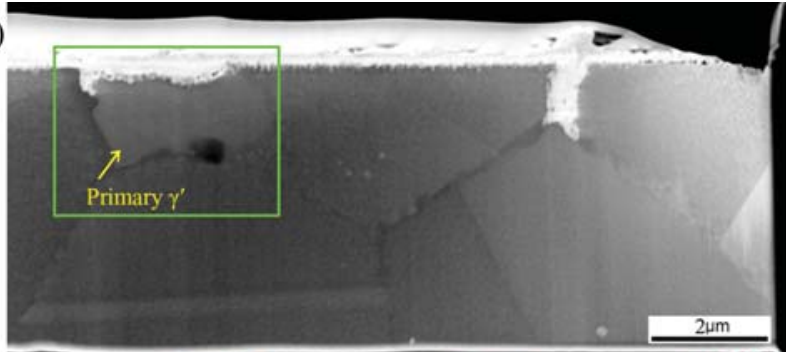

(b) N
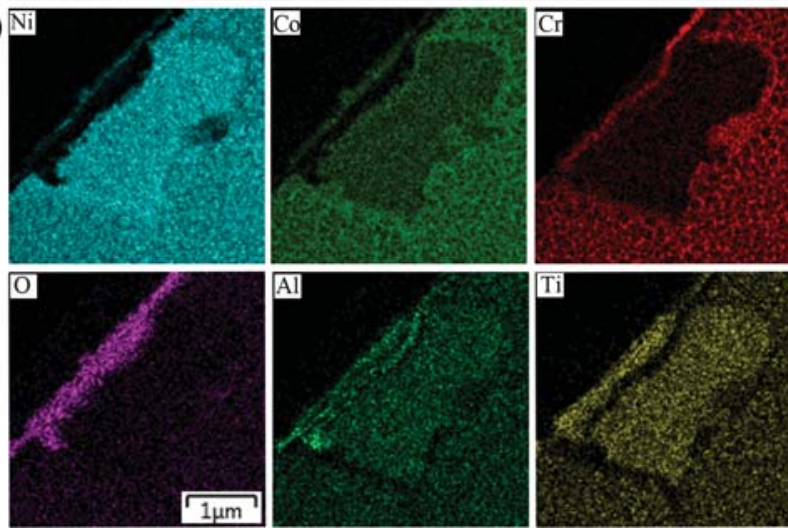

Figure 9 (a) SEM image showing oxidation around primary $\gamma^{\prime}$ and grain boundary in the TEM lamellar extracted by FIB in the FG LSHR tested at $725^{\circ} \mathrm{C}$ and (b) the corresponding elemental distribution of oxides around the primary $\gamma^{\prime}$ indicated the by arrow shown in (a). (Note: The elemental maps in (b) were obtained by EDX analysis in TEM and are re-orientated at $45^{\circ} c f$ to (a))

In order to examine the oxidation at the propagating crack tip, in-plane TEM lamellar was prepared at the crack tip region after metallographic sectioning of the tested LSHR at $725{ }^{\circ} \mathrm{C}$. As shown in Figure 10, an oxide layer is found along the crack wake, but it is arguable that this oxide layer may be formed before or after the cracking of the grain boundary. However, an uncracked oxide intrusion can be seen at the crack tip, which further supports the assumption of the oxide cracking leading to crack initiation and propagation. As shown in the elemental maps, the oxide intrusion mainly consists of $\mathrm{Co}$ and $\mathrm{Cr}$ oxides, but no evident $\mathrm{Al}$ and $\mathrm{Ti}$ are detected. In addition, an $\mathrm{Al}$ oxide is seen within the primary $\gamma^{\prime}$ and a Ti-rich precipitate is located at the $\gamma / \gamma^{\prime}$ interface. It seems that these $\mathrm{Al}$ oxide and Ti-rich precipitates are inherited from the manufacture processes.

\section{Discussion}

\section{Effects of oxidation on crack initiation}

Based on the observation of the notch roots and fracture surfaces, cracks predominantly initiate along grain boundaries in both CG and FG LSHR due to the oxidation effects under the investigated conditions, even though it is reported that crystallographic facet crack initiation and crack initiation at subsurface pore and internal inclusions have also been observed at elevated temperatures for the LSHR alloy [15]. This difference in crack initiation is probably ascribed to the relatively high strain achieved at the notch root in this study, which accelerates the oxidation process by lowering the thermal activation energy and providing more short-circuit paths for the diffusion of oxygen and oxide-forming elements. In addition, the oxidation at $\gamma / \gamma^{\prime}$ interfaces (Figures 2 (d) and (e)) in the FG LSHR also makes these regions become potential crack initiation sites, and the beneficial effects of primary $\gamma^{\prime}$ in resisting crack initiation and propagation observed at room temperature may vanish at elevated temperatures [21].
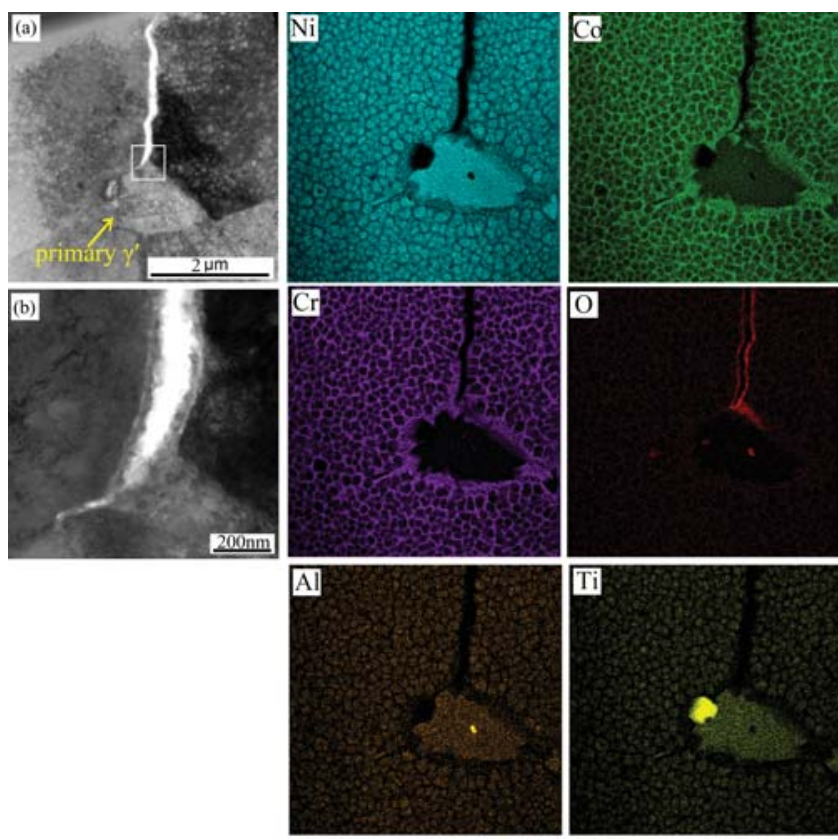

Figure 10 (a) TEM bright field image showing morphology of the crack tip in the FG LSHR at $725^{\circ} \mathrm{C}$ and the corresponding EDX elemental maps; and (b) TEM bright field image showing the close-up of the crack tip region highlighted in (a) by rectangle.

The oxide scales formed on the surface of the test piece during the fatigue test basically have the same constituents, i.e. an outer layer of $\mathrm{Ni} / \mathrm{Co}$ oxides, an inner layer of $\mathrm{Cr} / \mathrm{Ti} / \mathrm{Al}$ oxides. However, the significant differences are the depth of $\mathrm{Cr} / \mathrm{Ti} / \mathrm{Al}$ oxide intrusion and the bulged height of $\mathrm{Ni} / \mathrm{Co}$ oxides along the grain boundaries and $\gamma / \gamma^{\prime}$ interfaces. The longer oxide intrusion along a grain boundary and the higher bulged height of $\mathrm{Ni} / \mathrm{Co}$ oxides are usually associated with more significant mismatch strain and hence stress concentration. Therefore, intergranular crack initiation at elevated temperatures is closely related to the formation of the bulged grain boundary $\mathrm{Ni} / \mathrm{Co}$-rich oxides and $\mathrm{Cr} / \mathrm{Ti} / \mathrm{Al}$ oxide intrusion and subsequent oxide cracking, rather than the impingement of slip bands at oxygen-attacked grain boundaries. However, it should be noted that the impingement of slip bands at grain boundaries may enhance the diffusion of oxideforming elements and oxygen to some extent as slip bands can also provide short-circuit diffusion paths as grain boundaries [22]. But it seems that the effect of slip bands on the transportation of the oxide forming elements is quite limited compared with the grain boundaries, indicated by much more marked bulged $\mathrm{Ni} / \mathrm{Co}-$ rich oxides in the FG LSHR where limited slip bands exist.

It is not rare to see crack initiation assisted by oxide cracking in aeroengine $\mathrm{Ni}$ disk alloys. For instance, the porous Ni-oxide or $\mathrm{NiO} / \mathrm{Cr}_{2} \mathrm{O}_{3}$ oxide complex which has a spinel structure is frequently reported to cause crack initiation in disk alloy Inconel 718 [3, 4]. Additionally, the oxidation of $\mathrm{Nb}$ carbide to $\mathrm{Nb}$ oxide has also been observed as a potent crack initiation source due to 
the significant volume expansion during the transformation in Inconel 718 [23]. Intergranular crack initiation due to grain boundary oxidation are also observed in other disk alloys, such as Udimet ${ }^{\circledR} 500$ [24], 720Li [7], N18 [10], ME3 [25]. However, the oxides responsible for this intergranular crack initiation vary from alloy to alloy and depend on the test conditions. As shown in this study, the fatigue cracking here is caused by formation of the bulged $\mathrm{GB} \mathrm{Ni} / \mathrm{Co}$ oxides and $\mathrm{Cr} / \mathrm{Ti} / \mathrm{Al}$ oxide intrusion and subsequent cracking of these oxides, which is not widely reported, although it is expected that the formed $\mathrm{Ni} / \mathrm{Co}$ oxides may produce a surface ridging due to the outward diffusion during this oxide formation [24]. In fact, only Kitaguchi [13] has reported a Ni/Corich oxide formed ahead of the crack tip recently in the disk alloy RR1000 which has a similar Co content to the LSHR alloy in this study. Based on the present findings, this suggests that the oxidation of $\mathrm{Ni}$ and $\mathrm{Co}$ under cyclic load at elevated temperatures may be an important issue in such disk alloys and may accelerate crack initiation and propagation, especially in high Co-containing disk alloys. The use of Co to lower solvus temperature and increase yield strength through increased Co addition is not only a feature of the LSHR alloy investigated in this study but also RR1000 and TMW-4M3 [13, 15, 26].

\section{Effects of oxidation on short crack propagation}

Short fatigue crack propagation is quite sensitive to the microstructures ahead of the crack tip and the associated deformation behavior within the plastic zone [7, 10]. However, as temperature increases, this microstructure-sensitive short crack propagation becomes less dependent on the mechanical deformation process ahead of the crack tip, but more relies on the coupled oxidation-deformation interaction [16, 22]. At elevated temperatures, the barriers (i.e. grain boundaries and primary $\gamma^{\prime}$ precipitates) to crack propagation at room temperature now become preferential routes for crack propagation due to the selective oxidation at these regions. It is found that nearly all the surface cracks propagate along grain boundaries in the air tests for both CG and FG LSHR alloys predominantly via the coalescence of small grain boundary cracks (as shown in Figure 6). The majority of surface cracks also propagate along grain boundaries in the vacuum test for CG LSHR. Crack propagation along $\gamma / \gamma^{\prime}$ interfaces and/or cutting through the primary $\gamma^{\prime}$ in the FG LSHR is also observed due to oxidation. The predominant intergranular crack propagation at the surface is correlated to having sufficient oxygen supply and the highest strain achieved at the notch root surface, both of which can accelerate the occurrence of the oxidation. The crack propagation penetrating into the depth depends on microstructure, test temperature, oxygen partial pressure and the local strain at the crack tip. In general, FG LSHR exhibits predominantly intergranular fracture characteristics, whereas CG LSHR fracture surfaces are mainly characterized by mixed inter-transgranular features although the degree of intergranular feature increases with testing temperature. This difference between the morphology of fracture surface in CG and FG LSHR is mainly attributed to the more significant grain boundary oxidation occurring in the FG LSHR.

The transition from intergranular crack propagation to transgranular crack propagation in the depth direction is a consequence of the competing effects between oxidation and mechanical damage [6]. This transition predominantly depends on

\footnotetext{
${ }^{\circledR}$ Udimet is a registered trademark of Special Metals Corporation.
}

temperature and the local strain ahead of the crack tip. Immediately after crack initiation, the mechanical driving force for crack propagation is relatively low. Oxidation therefore has enough time to occur ahead of the crack tip, and this oxidation process is accelerated by the high temperature and high local strain, resulting in intergranular crack propagation. With increasing crack length, the mechanical driving force for crack propagation increases correspondingly, and the crack propagates at a higher speed and the time for oxidation processes to occur ahead of the crack tip is reduced for the same advancing increment of crack. Hence, the mechanical damage may start to outstrip the evolution of oxidation damage ahead of the crack tip, giving rising to transgranular crack propagation. The higher temperature and local strain ahead of the crack tip can delay this intergranular-transgranular transition to some extent. The influence of local strain on the transition between fracture modes has been further illustrated in a similar study on short crack initiation and propagation in Udimet $720 \mathrm{Li}$, where a transition from transgranular fracture to intergranular fracture is seen due to the relatively low initial strain and subsequent increase in local strain ahead of the crack tip (which gives rise to more significant oxidation effect ahead of the crack tip) [7]. However, a similar study on the disk alloy N18 (which has similar grain size to the FG LSHR) yields a predominantly transgranular fracture surface at both $650{ }^{\circ} \mathrm{C}$ and $725{ }^{\circ} \mathrm{C}$ when the same applied load was used, indicating the important influence of alloy composition on the oxidation processes ahead of the crack tip and the corresponding crack propagation modes [10].

\section{$\underline{\text { Mechanism of strain (stress)-assisted oxidation }}$}

As previously discussed, oxidation, especially at grain boundaries and $\gamma / \gamma^{\prime}$ interfaces, significantly enhances fatigue crack initiation and propagation in the LSHR alloy at elevated temperatures. The net effect of oxidation on fatigue crack initiation and propagation is a function of the microstructures of the investigated alloys, temperature, oxygen partial pressure and applied strain/stress [4, 6, 16, 22]. Generally, fine microstructure, high temperature, high oxygen partial pressure and high applied strain are associated with severe grain boundary and $\gamma / \gamma^{\prime}$ interface oxidation, producing more significant bulged/wide grain boundary $\mathrm{Ni} / \mathrm{Co}$-rich oxides in combination with the longer $\mathrm{Ti} / \mathrm{Cr} / \mathrm{Al}$ oxide intrusion along grain boundaries. Differences concerning the influence of microstructure, temperature and oxygen partial pressure on grain boundary oxide formation can be easily found by comparing the oxides in Figure 3. Although only one load condition was used in this study, the influence of the applied strain (stress) on oxidation can be seen in Karabela's study on RR1000 which shows the thickness of oxide scale increases with increased applied stress and the corresponding strain [27]. Moreover, high applied strain enhanced intergranular crack initiation is usually reported, which indirectly verifies the effect of applied strain on this oxidation process [15].

The oxidation features (i.e. bulged $\mathrm{GB} \mathrm{Ni} / \mathrm{Co}$ oxides and $\mathrm{Cr} / \mathrm{Ti} / \mathrm{Al}$ oxide intrusion along grain boundary) observed in the LSHR alloy at the notch root surface have a certain similarity to those observed ahead of the crack tip (where a plastic zone exists) observed in RR 1000 [13], but they differ from the surface oxide layers observed in RR 1000 without strain (stress) [28, 29]. In the strain/stress-free RR1000, the oxides formed at the specimen surface consist of a protective Ti-doped $\mathrm{Cr}_{2} \mathrm{O}_{3}$ layer but with rutile forming on its outer surface and a subsurface $\mathrm{Al} / \mathrm{Ti}$ oxide layer. 
Study of the isothermal oxidation of a similar disk alloy, i.e. ME3, also shows a $\mathrm{TiO}_{2}-\mathrm{Cr}_{2} \mathrm{O}_{3}$ external oxide layer with branched $\mathrm{Al}_{2} \mathrm{O}_{3}$ internal subscale that extended into a recrystallized $\gamma^{\prime}$ dissolution layer [25]. Generally, in the case where strain/stress is absent, oxidation usually begins with the formation of $\mathrm{Ni}$ oxide followed by chromia or $\mathrm{Ni}-\mathrm{Cr}$ oxide spinel along with the internal $\mathrm{Cr}_{2} \mathrm{O}_{3}$ or $\mathrm{Al}_{2} \mathrm{O}_{3}$ scale, which obeys the expected thermodynamic sequence. The discrepancy of oxidation between grain-interior and grain boundaries is insignificant, as the fast formation of the protective $\mathrm{Cr}_{2} \mathrm{O}_{3}$ or $\mathrm{Al}_{2} \mathrm{O}_{3}$ scale prevents the inward diffusion of $\mathrm{O}$ and outward diffusion of oxide-forming elements such as $\mathrm{Ni}$ and Co, which then prevents the further occurrence of internal and external oxidation. However, for strain/stress-assisted oxidation, as shown in this study, the discrepancy of oxidation between grain interior and grain boundary is much more significant than that observed in those strain/stress-free isothermal/dynamic oxidation tests [25, 27-30]. It is believed that these differences in oxidation are closely related to the accumulated strain or stress concentration around grain boundaries and $\gamma / \gamma^{\prime}$ interfaces.

It is clear that the global applied strain has an influence on the oxidation process. However, it seems that the oxidation process is more closely related to the accumulated local strain in this study as the fatigue process itself is usually associated with strain localization. In this study, apart from the significant discrepancy between grain-interior and GB oxidation, significant discrepancy of oxidation between different grain boundaries can be observed. As reported in a recent study, the bulged $\mathrm{Ni} / \mathrm{Co}$-rich oxides along with $\mathrm{Ti} / \mathrm{Cr} / \mathrm{Al}$ oxide intrusion preferentially form at the boundaries between high and low Schmid factor (SF) grains that are inclined normal to the tensile stress axis [14]. The preferential oxide formation at grain boundaries inclined normal to the tensile stress axis is attributed to the theory that tensile stress is beneficial in accommodating volume expansion during oxide formation/transformation [31]. Meanwhile, the accumulated local strain (or stress concentration) at grain boundaries or other interfaces are expected to change both the thermodynamics and kinetics of the oxidation process to some extent by providing the stored strain energy to overcome the barrier to oxide nucleation and by providing short-circuit diffusion paths (e.g. dislocations) to facilitate oxide-forming element diffusion, resulting in more significant oxidation.

Although the aforementioned discussion only provides a qualitative assessment of the influence of strain/stress on oxidation, it enables an insight into the mechanism of oxidation in the LSHR alloy under strain/stress during short fatigue tests and oxidation-assisted crack initiation and propagation. At the beginning/early stages of fatigue loading at elevated temperatures, surface oxidation occurs to form a thin $\mathrm{Ni} / \mathrm{Co}$ oxide scale due to the abundance of $\mathrm{Ni}$ and $\mathrm{Co}$ in alloy matrix and the higher formation rate of $\mathrm{Ni} / \mathrm{Co}$ oxides indicated by the higher parabolic rate constants [31]. Meanwhile, the strain is accumulating at boundaries between high and low SF grains. Due to the formation of surface $\mathrm{Ni} / \mathrm{Co}$ oxide scale, the internal oxidation (i.e. selective oxidation of $\mathrm{Cr}, \mathrm{Ti}$ and $\mathrm{Al}$ ) starts to occur as a consequence of the reduced oxygen partial pressure at the interface of the surface oxide scale/alloy matrix and the enrichment of $\mathrm{Cr}$, $\mathrm{Ti}$ and $\mathrm{Al}$ underneath the surface oxidation scale. Since there is strain accumulation at grain boundaries, this accelerates the internal oxidation process at these grain boundaries, producing an abundance of $\mathrm{Ni}$ and $\mathrm{Co}$ by consuming $\mathrm{Cr}$, $\mathrm{Ti}$ and $\mathrm{Al}$ (which is accompanied by dissolution of $\gamma^{\prime}$ precipitates). The abundant $\mathrm{Ni}$ and $\mathrm{Co}$ then migrate outward to form $\mathrm{Ni} / \mathrm{Co}$ oxides by shortcircuit diffusion along the grain boundaries of the oxides and the alloy matrix as well as dislocations formed during deformation process, resulting in the apparent bulged height at surface grain boundaries. In addition, the abundant $\mathrm{Ni}$ and $\mathrm{Co}$ also diffuse inwards to the internal oxide/alloy matrix interface where the dissolution of $\gamma^{\prime}$ precipitates is occurring and segregate there. The dissolution of $\gamma^{\prime}$ precipitates ahead of the internal oxide/alloy matrix interface also causes enrichment of $\mathrm{Ni}$ and $\mathrm{Co}$ at this region. As the load proceeds, the formed bulged $\mathrm{Ni} / \mathrm{Co}$ oxides and the $\mathrm{Cr} / \mathrm{Ti} / \mathrm{Al}$ oxide intrusion along the grain boundary start to crack, leading to crack initiation and propagation. When the crack propagates through the formed internal oxide intrusion, the oxygen can quickly access the crack tip which was the internal oxide intrusion tip (i.e. the internal oxide/alloy matrix interface) where it enriches in $\mathrm{Ni}$ and $\mathrm{Co}$. At this point, the enrichment of $\mathrm{Ni}$ and $\mathrm{Co}$ at the crack tip can result in rapid oxidation and form a quasi-surface oxidation scale. Consequently a new cycle of oxidation-oxide cracking-crack propagation starts.

\section{Conclusions}

Fatigue crack initiation and early short crack propagation behavior of the LSHR alloy at elevated temperatures were assessed by three-point bend loading with a replication procedure in combination with $\mathrm{OM}$ and SEM observation. An attempt has been made to reveal the influences of oxidation on fatigue crack initiation and propagation using FIB-TEM-EDX analysis. Based on the aforementioned results and discussion, the following conclusions can be made:

1. Fatigue lives of the LSHR alloy are shortened by high temperature and high oxygen partial pressure, which are associated with more intergranular fracture mechanisms. The FG LSHR possesses a longer fatigue life in most testing conditions although it is expected to be more severely GB oxidized, this is attributed to different strain levels expected in the notch root.

2. Plentiful crack initiation mainly occurs at GBs with bulged $\mathrm{Ni} / \mathrm{Co}$ oxides at elevated temperatures in the LSHR alloy due to oxide cracking. Cracks subsequently propagate along oxidized GBs at surface and exhibit significant crack coalescence at the final stages of fatigue life. In the depth direction, cracks predominantly propagate along grain boundaries in the FG LSHR at the investigated temperatures and in the CG LSHR at 725 ${ }^{\circ} \mathrm{C}$, whereas predominantly transgranular propagation after intergranular crack initiation appears in the $\mathrm{CG}$ LSHR at $650{ }^{\circ} \mathrm{C}$ either in vacuum or in air.

3. The oxides corresponding to crack initiation and propagation consist of bulged surface $\mathrm{Ni} / \mathrm{Co}$ oxides and $\mathrm{Cr} / \mathrm{Ti} / \mathrm{Al}$ oxide intrusion along grain boundaries and $\gamma / \gamma^{\prime}$ interfaces. Formation of bulged grain boundary $\mathrm{Ni} / \mathrm{Co}$ oxides and $\mathrm{Cr} / \mathrm{Ti} / \mathrm{Al}$ oxide intrusion is closely related to the strain localization which is associated with grain orientation and applied stress, and the formation of Ti and $\mathrm{Al}$ oxides in the intrusion are accompanied by dissolution of $\gamma^{\prime}$ precipitates. An enrichment of $\mathrm{Ni}$ and $\mathrm{Co}$ and a depletion of $\mathrm{Al}$ and $\mathrm{Ti}$ exist ahead of the oxide front due to the $\mathrm{Cr} / \mathrm{Ti} / \mathrm{Al}$ oxide intrusion formation. 


\section{Acknowledgements}

Thanks are due to the EPSRC (Grant EP/K027271/1) and China Scholarship Council for funding support, and to NASA for the supply of the LSHR alloys.

\section{References}

1. R.C. Reed, The Superalloys: Fundamentals and Applications (Cambridge, Cambridge University Press, 2006), 1-32.

2. T.M. Pollock, S. Tin, "Nickel-Based Superalloys for Advanced Turbine Engines: Chemistry, Microstructure and Properties," Journal of Propulsion and Power, 22 (2006), 361-374.

3. E. Andrieu, R. Molins, H. Ghonem, A. Pineau, "Intergranular crack tip oxidation mechanism in a nickel-based superalloy," Materials Science and Engineering: A, 154 (1992), 21-28.

4. R. Molins, G. Hochstetter, J.C. Chassaigne, E. Andrieu, "Oxidation effects on the fatigue crack growth behaviour of alloy 718 at high temperature," Acta Materialia, 45 (1997), 663-674.

5. D.G. Leo Prakash, M.J. Walsh, D. Maclachlan, A.M. Korsunsky, "Crack growth micro-mechanisms in the IN718 alloy under the combined influence of fatigue, creep and oxidation," International Journal of Fatigue, 31 (2009), 1966-1977.

6. R. Jiang, S. Everitt, M. Lewandowski, N. Gao, P.A.S. Reed, "Grain size effects in a Ni-based turbine disk alloy in the time and cycle dependent crack growth regimes," International Journal of Fatigue, 62 (2014), 217-227.

7. H. T. Pang, P. A. S. Reed, "Microstructure effects on high temperature fatigue crack initiation and short crack growth in turbine disk nickel-base superalloy Udimet 720Li," Materials Science and Engineering: A, 448 (2007), 67-79.

8. J. Telesman, T. P. Gabb, A. Garg, P. Bonacuse, J.Gayda, "Effect of Microstructure on Time Dependent Fatigue Crack Growth Behavior In a P/M Turbine Disk Alloy," In Superalloys 2008, edited by R. C. Reed, K. A. Green, P. Caron, T. P. Gabb, M. G. Fahrmann, E. S. Huron, etc, TMS, Warrendale, PA (2008), PP. $807 \sim 816$

9. T.P. Gabb, J. Gayda, J. Telesman, L.J. Ghosn, A. Garg, "Factors influencing dwell fatigue life in notches of a powder metallurgy superalloy," International Journal of Fatigue, 48 (2013), 55-67.

10. R. Jiang, S. Everitt, N. Gao, K. Soady, J.W. Brooks, P.A.S. Reed, "Influence of oxidation on fatigue crack initiation and propagation in turbine disk alloy N18," International Journal of Fatigue, 75 (2015), 89-99.

11. J.A. Pfaendtner, C.J. McMahon Jr, "Oxygen-induced intergranular cracking of a Ni-base alloy at elevated temperatures-an example of dynamic embrittlement," Acta Materialia, 49 (2001), 3369-3377.

12. U. Krupp, W.M. Kane, C. Laird, C.J. McMahon, "Brittle intergranular fracture of a Ni-base superalloy at high temperatures by dynamic embrittlement," Materials Science and Engineering: A, 387-389 (2004), 409-413.

13. H.S. Kitaguchi, H.Y. Li, H.E. Evans, R.G. Ding, I.P. Jones, G. Baxter, P. Bowen, "Oxidation ahead of a crack tip in an advanced Ni-based superalloy," Acta Materialia, 61 (2013), 1968-1981.

14. R. Jiang, N. Gao, P.A.S. Reed, "Influence of orientationdependent grain boundary oxidation on fatigue cracking behaviour in an advanced Ni-based superalloy," J Mater Sci, 50 (2015), 4379-4386.

15. T. P. Gabb, J. Gayda and Jack Telesman, "Thermal and Mechanical Property Characterization of the Advanced Disk Alloy LSHR" (NASA/TM-2005-213645, 2005).

16. A. Pineau, S.D. Antolovich, "High temperature fatigue of nickel-base superalloys - A review with special emphasis on deformation modes and oxidation," Engineering Failure Analysis, 16 (2009), 2668-2697.

17. T.P. Gabb, P.T. Kantzos, J. Telesman, J. Gayda, C.K. Sudbrack, B. Palsa, "Fatigue resistance of the grain size transition zone in a dual microstructure superalloy disk," International Journal of Fatigue, 33 (2011), 414-426.

18. H.Y. Li, J.F. Sun, M.C. Hardy, H.E. Evans, S.J. Williams, T.J.A. Doel, P. Bowen, "Effects of microstructure on high temperature dwell fatigue crack growth in a coarse grain PM nickel based superalloy," Acta Materialia, 90 (2015), 355-369.

19. S.L. Semiatin, K.E. McClary, A.D. Rollett, C.G. Roberts, E.J. Payton, F. Zhang, T.P. Gabb, "Microstructure Evolution during Supersolvus Heat Treatment of a Powder Metallurgy Nickel-Base Superalloy," Metall and Mat Trans A, 43 (2012), 1649-1661.

20. T. P. Gabb, J. Gayda, J. Telesman, A. Garg, "The effects of heat treatment and microstructure variations on disk superalloy properties at high temperature," In Superalloys 2008, edited by R. C. Reed, K. A. Green, P. Caron, T. P. Gabb, M. G. Fahrmann, E. S. Huron, etc, TMS, Warrendale, PA (2008), pp. 121-130.

21. R. Jiang, N. Karpasitis, N. Gao, P.A.S. Reed, "Effects of microstructures on fatigue crack initiation and short crack propagation at room temperature in an advanced disk superalloy," Materials Science and Engineering: A, 641 (2015), 148-159.

22. H. Ghonem, T. Nicholas, A. Pineau, "Elevated temperature fatigue crack growth in alloy 718-part II: effects of environmental and material variables," Fatigue \& Fracture of Engineering Materials \& Structures, 16 (1993), 577-590.

23. T. Connolley, P.A.S. Reed, M.J. Starink, "Short crack initiation and growth at $600{ }^{\circ} \mathrm{C}$ in notched specimens of Inconel718," Materials Science and Engineering: A, 340 (2003), $139-154$

24. C.J. McMahon, L.F. Coffin, "Mechanisms of damage and fracture in high-temperature, low-cycle fatigue of a cast nickelbased superalloy," Metallurgical Transactions, 1 (1970), 34433450 . 
25. C.K. Sudbrack, S.L. Draper, T.T. Gorman, J. Telesman, T.P. Gabb, D.R. Hull, "Oxidation and the Effects of High Temperature Exposures on Notched Fatigue Life of an Advanced Powder Metallurgy Disk Superalloy," in Superalloys 2012, edited by E. S. Huron, R. C. Reed, M. C. Hardy, M. J. Mills, R. E. Montero, P. D. Portella, J. Telesman, TMS, Warrendale, PA (2012), pp. 863-872.

26. Y. Yuan, Y.F. Gu, T. Osada, Z.H. Zhong, T. Yokokawa, H. Harada, "Deformation mechanisms in a new disk superalloy at low and intermediate temperatures," Scripta Materialia, 67, (2012) 137-140.

27. A. Karabela, L.G. Zhao, J. Tong, N.J. Simms, J.R. Nicholls, M.C. Hardy, "Effects of cyclic stress and temperature on oxidation damage of a nickel-based superalloy," Materials Science and Engineering: A, 528 (2011), 6194-6202.

28. S. Cruchley, H.E. Evans, M.P. Taylor, M.C. Hardy, S. Stekovic, "Chromia layer growth on a Ni-based superalloy: Subparabolic kinetics and the role of titanium," Corrosion Science, 75 (2013), 58-66.

29. A. Encinas-Oropesa, G.L. Drew, M.C. Hardy, A.J. Leggett, J.R. Nicholls and N.J. Simms, "Effects of oxidation and hot corrosion in a nickel disk alloy," In Superalloys 2008, edited by R. C. Reed, K. A. Green, P. Caron, T. P. Gabb, M. G. Fahrmann, E. S. Huron, ect, TMS, Warrendale, PA (2008), pp. 609-618.

30. J.H. Chen, P.M. Rogers, J.A. Little, "Oxidation behavior of several chromia-forming commercial nickel-base superalloys," Oxid Met, 47 (1997), 381-410.

31. N. Birks, G. H. Meier, F. S. Pettit, Introduction to the High Temperature Oxidation of Metals (Cambridge, Cambridge University Press, 2009), 39-74. 